\title{
Uso comum da terra e práticas associativistas da população cabocla do planalto catarinense
}

\author{
Marlon Brandt \\ Nazareno José de Campos ${ }^{* *}$
}

\section{Resumo}

No Planalto Catarinense, se estabeleceu desde fins do século XVIII, uma significativa parcela de pequenos e médios sitiantes, na maioria posseira, que viviam às margens dos latifúndios pastoris das áreas de campos naturais. Sua fonte de renda básica se ligava a agricultura de subsistência e práticas ligadas à exploração de recursos em comum de campos, pinheirais e ervais nativos. $\mathrm{O}$ acesso a estes recursos, da mesma forma que a posse da terra e a vida social, era regulado por práticas, normas e costumes, impossíveis de serem apreciadas somente pelo viés econômico, as quais eram transmitidas de geração a geração, onde a oralidade e o direito costumeiro exerciam uma importância fundamental. Isso vai se desestruturando, à medida que uma nova dinâmica sócioespacial, ligada à economia capitalista vai se instaurando na região, frente aos novos condicionantes espaciais que se fazem sentir, como a colonização, a propriedade legal, o cercamento das terras e a devastação das florestas.

Palavras-chave: Uso comum da terra, práticas associativistas, colonização.

\footnotetext{
* Mestrando do Programa de Pós-Graduação em Geografia da Universidade Federal de Santa Catarina (marlonbrandt@yahoo.com.br).

** Professor do Departamento de Geociências da Universidade Federal de Santa Catarina (nazareno@cfh.ufsc.br).
}

Geosul, Florianópolis, v. 23, n. 45, p 43-64, jan./jun. 2008 
BRANDT, M. \& CAMPOS, N.J. Uso comum da terra e práticas ...

Communal use of the land and associated-activist practices of cabocla population of the Santa Catarina Plateau

\begin{abstract}
Besides the proprietors of a large quantity of land, one significant portion of small and medium dwellers inhabited the Plateau of Santa Catarina. Most of them were squatters who lived at the marginal side of bucolic land properties of areas of natural fields. They made their principal source of living upon subsistence agriculture and in practices connected to the exploitation of communal resources of the fields, pine trees and native herbal trees. The access to those resources, as well as the possession of the land and the social life, which were transmitted from generation to generation in which orality and customary rights exerted fundamental importance, were regulated by means of practices, norms and habits, which were impossible to be assessed only by economic means. This undergoes a process of destabilization, as a new socio-spatial dynamics connected with the capitalist economy starts to be established in the region due to the new spatial circumstantial factors that become perceptible such as colonization, the legal property, the demarcation of the estates and the devastation of forests.
\end{abstract}

Key words: Communal use of the land; associated-activist practices; colonization

\title{
Considerações iniciais
}

A região do planalto sul brasileiro possui uma formação natural característica, constituindo-se num espaço cujas altitudes variam entre os 600 e 1000 metros aproximadamente, dominando uma vegetação nativa de campos e floresta de araucárias, ora um misto de ambas, com presença ainda de ervais (erva-mate) e misto de arbustos e vegetação rasteira regionalmente conhecidos por faxinais. Essa complexidade físico-natural refletiu no processo de formação e dinâmica econômico-social regional através do 
BRANDT, M. \& CAMPOS, N.J. Uso comum da terra e práticas ...

desenvolvimento das economias do gado, ervateira e madeireira, feições básicas que se mostram presentes na área de planalto do território catarinense.

Embora o aspecto geral da formação sócio-espacial do planalto catarinense seja importante para a sua compreensão, o que neste momento interessa mais diretamente é analisar os elementos básicos identificadores do costume e cultura popular da população planaltina conhecida como "cabocla", no período específico entre a constituição e desenvolvimento da economia tropeira e o pósContestado, onde observa-se a consolidação do processo de colonização, aprofundando a problemática social de toda a região.

Nesse sentido, a análise do tema-objeto de estudo, num tempo histórico definido, requer a compreensão de elementos da história, geografia, antropologia, sociologia, economia, direito, entre outros, visto que entre a população tradicional que habitava a região, são observadas práticas, normas e costumes que não podem ser vistos apenas, por exemplo, pelo viés econômico. Consistem em heranças transmitidas de geração a geração, cuja oralidade exercia fundamental importância, qual seja, "crenças não escritas, normas sociológicas e usos asseverados na prática, mas jamais registrados por qualquer regulamento", segundo afirma E. P. Thompson (2002, p. 88). Assim, não se restringirá apenas às normatizações jurídicas definidas pelo direito positivo, mas, também, se tomará por base as atribuições e definições realizadas a

\footnotetext{
${ }^{1} \mathrm{O}$ termo é utilizado da mesma forma que o fez Paulo Pinheiro Machado em sua obra intitulada "Lideranças do Contestado". Embora, conforme o autor "não haja uma conotação étnica nesta palavra, freqüentemente o caboclo era mestiço, muitas vezes negro. Mas a principal característica desta palavra é que distingue uma condição social e cultual, ou seja, são caboclos os homens pobres, pequenos lavradores posseiros, agregados ou peões". Posteriormente, com as primeiras levas de imigrantes oriundos da Alemanha e da Polônia, a partir da segunda década do século XIX, passam também estes a se "acaboclarem", adquirindo muitos hábitos e costumes daquela população, como os métodos agrícolas e a devoção a João Maria (2004, p. 48).
} 
BRANDT, M. \& CAMPOS, N.J. Uso comum da terra e práticas ...

partir do chamado direito costumeiro (CAMPOS, 2002), situação bastante comum entre populações tradicionais, revelados em seus hábitos, costumes e inter-relações sociais.

\section{Ocupação do planalto catarinense: formação e dinâmica da economia tropeira}

Originariamente o Planalto Catarinense era ocupado por grupos indígenas, pertencentes principalmente a populações do tronco cultural Jê. A chegada do homem branco dá-se inicialmente de modo efêmero, por elementos originários das populações ibéricas (lusitanos e espanhóis), muitas das quais provenientes da província de São Paulo à procura de alguma forma de riqueza, aí incluindo a escravização dos indígenas.

Com a formação da economia aurífera nas Minas Gerais, o Sul, especialmente as suas áreas de planalto, passam a ter visibilidade perante os interesses da coroa portuguesa, haja vista a presença de imensas pastagens naturais, integrando assim a região a uma evidente divisão territorial do trabalho, como abastecedora de gado vivo e subprodutos deste para o mercado daquela formação econômica. Gradativamente vai se formando, a partir do século XVIII, a economia tropeira, tendo por base, de um lado, as grandes fazendas e estâncias de produção (Rio Grande do Sul, Santa Catarina e Paraná), e de outro, o grande mercado comprador, as feiras, como a conhecida Feira de Sorocaba (São Paulo), onde parte era então repassada à região aurífera de Minas, Goiás e Mato Grosso.

Por outro lado, apesar do sistema de sesmarias se constituir, por todo o período colonial no país, na característica fundiária dominante, na prática, o regime de posse dominava entre a população em geral. Aqui no Sul, nas regiões de planalto, como no Planalto Lageano e Planalto Norte em Santa Catarina, isso não foi diferente. Entretanto, é perceptível, em sua formação econômica, relação social e de produção bastante diferente do ocorrido em outras áreas do país, mesmo onde dominava o latifúndio. Se as relações de produção (como por exemplo nas Minas Gerais em 
BRANDT, M. \& CAMPOS, N.J. Uso comum da terra e práticas ...

relação ao ouro, e no Nordeste em relação a cana de açúcar) eram dominantemente escravistas, aqui no sul, nas áreas de planalto, a escravidão teve menor importância, apesar de também ter ocorrido. Delineou-se assim a formação e desenvolvimento de relações sociais e de produção caracterizada pela relação entre os agregados e os proprietários das fazendas.

Todavia, a formação social da região não era constituída apenas por proprietários das fazendas e seus agregados. Uma considerável população posseira, vivendo às margens das grandes fazendas e áreas de matas e faxinais, de pouca valia para o fazendeiro, também se fazia presente, mas que podia igualmente ter (ou não) laços de apadrinhamento em relação àquele. Trata-se de uma população fortemente miscigenada (índio, branco e negro), conhecida por cabocla, que possuía, como veremos a seguir, inúmeras práticas sociais onde havia forte presença do coletivo em relação ao individual.

\section{Costumes, uso comum da terra e práticas associativistas}

Entre as populações caboclas do planalto catarinense na época de domínio do tropeirismo, até o momento imediatamente anterior e posterior ao conflito do Contestado, percebe-se, de forma constante, práticas que identificam aspectos do coletivo, sendo uma das mais importantes as práticas de uso comum da terra.

$\mathrm{Na}$ visão leiga do passado, e mesmo integrada a boa parte da historiografia tradicional, há a idéia muito comum de que aquelas populações viviam isoladas, tanto uns dos outros quanto do mundo. $\mathrm{Na}$ verdade, estas se constituíam em uma população integrada à vizinhança, mesmo que em escalas diferentes, num tipo de povoamento disperso, cujo habitante possuía, segundo nos lembra Antônio Cândido em sua obra sobre os parceiros do Rio Bonito, "formas de sociabilidade em função dele, e não de núcleos concentrados, de que dependem num outro plano de relações" (1971, p. 58), apresentando um forte sentimento de construção, por si próprio, do lugar. 
BRANDT, M. \& CAMPOS, N.J. Uso comum da terra e práticas ...

Lugar que, para aquela população, é "cheio de objetos comuns", segundo aponta João Baptista de Mello, onde ela se sente segura e a vontade, emergindo assim suas experiências cotidianas, de trabalho, lazer e sobrevivência (1993, p. 32). Antônio Cândido defende que a formação do lugar para a população que nele vive "depende não apenas da posição geográfica, mas também do intercâmbio entre famílias e as pessoas" onde a "convivência entre eles decorre da proximidade física e a necessidade de cooperação" (1971, p. 64-65). Nesse sentido decorre, entre a comunidade, um forte sentimento do coletivo, conjugando-se a elementos característicos das ações, usos e direitos de caráter privado, em que observa-se um controle dos recursos básicos pela população, que se efetiva, nas palavras de Alfredo Wagner de Almeida,

através de normas estabelecidas, combinando uso comum de recursos e apropriação privada de bens, que são acatadas, de maneira consensual, nos meandros das relações sociais estabelecidas entre vários grupos familiares que compõem uma unidade social (2004, p. 10).

Estes hábitos e costumes da população sertaneja, vistos como uma ambiência, podem ser compreendidos, como aponta E. P. Thompson, com a ajuda do conceito de habitus exposto por Pierre Bourdieu, consistindo, na visão de Thompson, em "um ambiente vivido que inclui práticas, expectativas herdadas, regras que não só impunham limites aos usos como revelam possibilidades, normas e sanções, tanto da lei como das pressões da vizinhança" (2002, p.90), sendo este um esquema durável, porém flexível, tendendo, como aponta Sérgio Miceli,

ao mesmo tempo, a reproduzir as regularidades inscritas nas condições objetivas e estruturais que presidem a seu princípio gerador, e a permitir ajustamentos e inovações às exigências postas pelas situações concretas que põem à prova sua eficácia.

O habitus, assim visto no entender do autor, "completa o movimento de interiorização das estruturas exteriores, ao passo 
BRANDT, M. \& CAMPOS, N.J. Uso comum da terra e práticas ...

que as práticas dos agentes exteriorizam os sistemas de disposições incorporadas" (2003, p. XL-XLI).

Se de um lado o uso da terra e de recursos naturais possui uma antiguidade que remonta tanto a população indígena quanto a ocupação lusa do planalto, incluindo aí populações de origem africana, as formas de uso e demais aspectos sócio-culturais continuaram sendo retransmitidos pela população geração após geração.

Entre uma das atividades e usos voltados ao coletivo destaca-se a criação de animais em comum, prática cuja integração entre vizinhança se fazia sentir. Criado solto, o animal circulava livremente nas terras, compreendidas por campos e florestas, ocupadas oficialmente ou por posse, além das devolutas. O arrebanhamento, de bois, cabras ou porcos, tanto para consumo quanto para a venda, era facilitado pelo contato entre os moradores, que tinham o hábito de avisar ao proprietário se alguns deles encontravam-se percorrendo suas terras, prática assim descrita por Sebastião Pires, morador do município de Fraiburgo:

é, tinha boi para tudo quanto era lado. Quando ele queria requisitar a boiada, lá em tal lugar tem dois três bois que tá lá no terreno do fulano, mais três quatro no outro terreno, ele buscava. Criava em aberto (2005).

Também através de textos de militares que percorreram a região do Planalto durante a Guerra do Contestado é possível se perceber a criação em comum de animais soltos em campos e matas. Cite-se como exemplo o Capitão Vieira da Rosa, que em suas notas publicadas no jornal Terra Livre, de Florianópolis, sob o título de "Reminiscências da Campanha do Contestado - subsídios para a História", fez comentários sobre a criação de animais soltos (no caso porcos), procedendo também a interessante descrição de como a paisagem, com seus campos, faxinais e florestas, se apresentava na época, além de mencionar a posse das melhores pastagens dos campos naturais por parte de ricos fazendeiros: 
BRANDT, M. \& CAMPOS, N.J. Uso comum da terra e práticas ...

[...] esses mattos, limpos de cipos, gramados, permittindo passear por ellas a cavallo, como nalgum parque europeu, os fructos nutritivos são abundantes, entre os quaes os guamirins, o vacum, as goiabas serranas, os araçás, a imbuia, o pinhão, as amoras e o butiá, constituem o alimento principal para engorda de suínos.

O butiá vegeta expontaniamente numa area não muito dilatada: começando a apparecer junto à villa [de Curitibanos], nos campos de Antônio Sampaio, prolonga-se pelo Guarda-mór, atravessa o Correntes, acompanha o Butiásinho e parte do Espinilho, volta pela Liberata, Butiá Verde, Bahia, Taboão, Perdizes, Trombudo e Fachinal das Aguas, onde de approxima de novo do Guarda-mór tendo descripto um circulo de 20 leguas mais ou menos.

A descripção que fizemos das terras curitibanenses explica: primeiro o modo de vida do caboclo que, tendo a creação de porcos como sua principal e unica industria era obrigado a viver pelos ermos, no meio das mattas; segundo, a difficuldade que as forças do governo encontraram nas marchas e no serviço de intendência.

Os terrenos limpos, de campos, são todos propriedades de ricos fazendeiros que, cuidando também da lavoura, possuem outras terras no que chamam serras, terras de matto. Para os de Guarda Mór e para todos que ficam situados ao sudoeste da villa, essas terras de planta estão nas mattas da margem direita do Correntes, excellentes para todos os cultivos, sem excepção (VIEIRA DA ROSA, 1918, p. 1).

Já o Primeiro-Tenente do Exército, Herculano Teixeira D'Assumpção, que atuou na coluna Sul, entre 1914 e 1915, fez, em sua obra sobre o conflito, a seguinte observação a respeito da criação de animais:

A criação suína e caprina é notável; durante as nossas operações militares, encontramos, por todo o sertão, muitos animaes porcinos abandonados na matta, comeno exclusivamente pinhão, e, no reductinho do trombudo, a 9 $\mathrm{Km}$ a sudeste de Perdizinhas, para mais de 100 bodes, cabras e cabritos, também em completo abandono. É regular a criação de ovinos, para o qual bem se presta a 
BRANDT, M. \& CAMPOS, N.J. Uso comum da terra e práticas ...

temperatura dos campos catharinenses collocados no planalto brasileiro. É, pois digno de registro o progresso do gado lanígero no Estado (D’ASSUMPÇÃO, 1917, p. 181).

É possível que o termo atribuído àqueles animais como sendo "abandonados", não seja empregado apenas pelo fato de que parte da população tenha se deslocado aos redutos em decorrência do conflito do Contestado, mas, também, à forma com que os animais eram criados, soltos, como os porcos, sobrevivendo principalmente de pinhões e outros produtos da mata. Adiante o autor também tece comentários a respeito da compra de animais, onde alguns criadores compravam pequenos rebanhos, muitos de pequenos criadores e posseiros, para formar então "o grosso" do negócio para a venda, cujos animais, conduzidos em tropa, poderiam, por exemplo, seguir rumo ao Vale do Itajaí. Em relação aos bovinos, este, também solto, era aprisionado uma ou duas vezes por ano na mangueira, para a ingestão de sal, quando eram então marcados (D’ASSUMPÇÃO, 1917, p. 190-206).

Mesmo se tratando de uma região de fronteira, a população, como aponta Paulo Pinheiro Machado, formada por pequenos e médios sitiantes, muitos posseiros, era relativamente fixa, ao menos em parte do século XIX e nas primeiras duas décadas do século XX. A seu ver, a proximidade dos ervais nativos e a produção pastoril, onde também é possível incluir a questão daquilo que Antônio Cândido apontou como "sentimento de localidade", em parte formado através dos laços de parentesco e compadrio, não apenas na localidade, mas também em áreas próximas, são fatores relevantes na sedentarização do sertanejo ${ }^{2}$.

$\mathrm{O}$ acesso a terra, no entanto, tornava-se mais precário à população de pequenos sitiantes, à medida que a apropriação

2 Segundo Paulo Pinheiro Machado, no início da década de 1890, a localidade de Taquaruçu, hoje pertencente ao município de Fraiburgo, já apresentava, em seu povoado, um certo adensamento demográfico, com moradores provenientes de diversas ocupações e origens, onde já existiam moradores nascidos há mais de duas décadas na localidade (2004, p. 87). 
BRANDT, M. \& CAMPOS, N.J. Uso comum da terra e práticas ...

privada, tanto por concessões quanto por grilagens, não mais somente em relação as grande extensões de campos naturais, mas também aos faxinais e matas, muitas compostas por ervais nativos, tornava-se crescente, sobretudo no Norte e Centro das regiões de Campos Novos e Curitibanos, que seria acrescida à atuação de empresas como a Brazil Railway e a Lumber Company (MACHADO, 2004, p. 75).

$\mathrm{Na}$ região de Lages, ainda nas primeiras décadas do século $\mathrm{XX}$, antes mesmo do processo de colonização, Paulo Pinheiro Machado aponta o caso de uma localidade onde o gado bovino de grandes fazendas de criação ainda não cercadas adentravam as áreas de matas e faxinais, acarretando na destruição da lavoura de pequenos sitiantes, muitos posseiros. No município ${ }^{3}$, este conflito era mais freqüente em áreas próximas a São José do Cerrito, onde pequenos sitiantes eram vizinhos de grandes proprietários. Isso não quer dizer, no entanto, que toda a criação bovina, ao menos em Lages, fosse solta. Já existiam muitas taipas de pedra separando invernadas, da mesma forma que as terras de um ou outro criador. No ano de 1904, foi promulgada uma lei municipal que regulava as matas disponíveis aos criadores e a área destinada ao plantio, que inicialmente era de seis quilômetros mata adentro para os criadores, reduzidos em 1912, para três quilômetros. Como aponta o autor anteriormente referido, a promulgação da Lei evidencia o poder dos criadores sobre os lavradores, pois os primeiros, por possuírem melhor condição econômica frente aos pequenos sitiantes, possuíam representação política no Conselho Municipal. No entanto, a redução da área para três quilômetros, em 1912, "revela certa força política e legitimidade por parte dos pequenos lavradores" (MACHADO, 2004, p. 75-76).

Ao que tudo indica, esta disputa e invasão da criação por parte de grandes fazendeiros, parece ser um caso muito mais específico da região de Lages, onde a quantidade de campos era muito maior do que em outras áreas mais a norte e a oeste, para

\footnotetext{
${ }^{3}$ Lages à época era um município muito extenso, dominando grande área da região de planalto em Santa Catarina.
} 
BRANDT, M. \& CAMPOS, N.J. Uso comum da terra e práticas ...

onde inclusive muitos daqueles moradores acabaram migrando, cujas "matas eram muitas e os campos e o poder dos coronéis, mais escassos" segundo igualmente define Paulo P. Machado. Mas isso não quer dizer que nas áreas onde a existência de campos era reduzida ocorresse um menor número de disputas por terra, como em algumas áreas ao norte e oeste de Curitibanos, e não apenas envolvendo a questão do avanço da criação na lavoura.

Por outro lado, além da criação de animais em comum existiam outras formas de solidariedade existentes, cujo exemplo mais presente é o mutirão ${ }^{4}$, conhecido popularmente na região como puxirão, cujo termo envolve também outras variações regionais, como ajuntório, muxirão, putirão, pixirão, etc.

Trata-se de uma prática que ocorria e ocorre em diversas regiões do Brasil, possuindo origem antiga, conforme apontam autores como Clovis Caldeira e Artur Ramos, com diferenciações no espaço e no tempo, tanto pelas sociedades nativas da América, quanto da África e da Europa, que trouxeram ao Brasil cada uma a sua experiência de práticas coletivas (CALDEIRA; RAMOS, 1938). O mutirão, como aponta Antônio Cândido, é um dos elementos que, no caso do trabalho agrícola, o morador rural recorre, por exemplo, para a abertura de um roçado, a ajuda dos vizinhos, "suprimindo as limitações da atividade individual ou familiar" (1971, p. 68).

Depoimentos de antigos moradores da região de Fraiburgo dão conta da existência do puxirão entre as famílias, sendo que tal forma de solidariedade entre moradores tenha vindo possivelmente com os primeiros ocupantes da região. Além da cooperação na faina agrícola, destaca-se o aspecto festivo desta prática, o que segundo Antônio Cândido, era fundamental na "formação duma rede ampla de relações, ligando uns aos outros os habitantes do

\footnotetext{
${ }^{4}$ Conforme o Boletim do Conselho Nacional de Geografia de maio de 1943, o mutirão se caracteriza como "uma cooperação mútua entre agricultores, usada, principalmente, nas paragens onde o trabalho remunerado é quase desconhecido, nas zonas de pequenas e médias propriedades ou de terras desvalorizadas" (p. 39).
} 
BRANDT, M. \& CAMPOS, N.J. Uso comum da terra e práticas ...

grupo de vizinhança". Se os homens, durante o puxirão se encarregavam do trabalho no campo, limpando roça, por exemplo, as mulheres ficavam encarregadas, como aponta Maria José Cordeiro, antiga moradora da região, com 91 anos de idade, da preparação da alimentação, onde o dia terminava com festividades:

Fazia aqueles puxirão fazia de tudo, $[\ldots]$ coisa mais linda aqueles bailes. [...] Fazia aquele mundo de quirera pro puxirão, fazia bastante arroz, e de noite tinha o baile (2005).

Enfim, o mutirão, assim como outros costumes que integravam a cultura popular, e que permaneciam na memória oral, eram igualmente transmitidos através de músicas, décimas ou simplesmente "causos". Além destas influências, muito deste costume tradicional do planalto, conforme Paulo Pinheiro Machado,

era balizado religiosamente pelos ensinamentos do monge João Maria como se fosse mandamentos para uma boa vida no sertão, baseada em valores como o respeito, a defesa da vida e da honra, a lealdade, a sinceridade e o equilibro (2004, p. 96).

Nesse sentido, pode-se afirmar que a cultura da população planaltina assume formas conservadoras, embora esta não possa ser vista como imutável, que procura recorrer aos costumes tradicionais e busca, de certa forma, reforçá-los. Isto pode ser percebido inclusive no trato com a natureza, conforme evidencia Euclides Felippe em seu estudo sobre o folclore da região do Contestado, em que apresenta alguns preceitos do monge, muitos deles relacionados ao uso dos recursos da natureza, colhidos pelo Capelão Emídio Conceição, do Faxinal do Paulista, "os quais ouvira daqui e ali" e que serão em parte transcritos:

1) Não se deve queimar folhas, cascas nem palhas das plantações que dão mantimentos. $O$ que a terra dá emprestado, quer de volta.

5) As casas e as propriedades de quem incendeia as matas, um dia também hão de virar em cinzas. 
BRANDT, M. \& CAMPOS, N.J. Uso comum da terra e práticas ...

11) Bicho do mato é filho da terra. Só se matam os danosos.

12) Bicho do mato não traz marca de gente. Pertence à Mãe Natureza. Quem caça por divertimento, caça o alheio. É criminoso. Será punido.

16) Não se tira leite, sem deixar um teto cheio ao terneiro.

17) Não se tira mel, sem deixar alguns favos para as abelhas (2005, p. 36-37).

Mesmo que, embora atribuídos a figura de João Maria, possam não ter sido proferidos pelo monge, o respeito que a população possuía pelos seus ensinamentos poderia dar uma certa legitimidade a estes e outros mandamentos, fazendo também modificações e acréscimos, onde, como aponta Elio Serpa, a "tradição encarregou-se de preservar a memória dos profetas e seus ensinamentos que, até hoje, ainda são cultuados na região" (1999, p. 32). Mandamentos e idéias, que, atribuídas ao monge, "embutiam uma concepção do que deveria ser considerado tradicionalmente correto no trato entre as pessoas, uma 'economia moral" "'5 da população cabocla (2004, p. 98).

Cabe ressaltar que, apesar do conflito do Contestado e de toda a situação que se seguiu ter sido bastante penosa para uma considerável população constituída por posseiros, agregados, sitiantes, etc, muitos dos hábitos e costumes permaneceram. Porém mostram-se cada vez mais sujeitos as interferências de novos interesses, grande parte ligados à expansão capitalista sobre a região, possibilitando, em especial mais recentemente, em muitas situações e/ou contextos, o completo desaparecimento.

\footnotetext{
${ }^{5}$ A economia moral de uma população possuía, de acordo com E. P. Thompson, "uma visão consistente tradicional das normas $e$ obrigações sociais", que não pode ser descrita como "política" em nenhum sentido avançado, mas também não devemos entendê-la como apolítica, "pois supunha noções definidas, e apaixonadamente defendidas do bem-estar comum" (2002, p. 152-153). Baseia-se, segundo Frederico de Castro Neves, "em concepções morais pouco influenciadas pelas noções de lucro e acumulação ilimitada de riquezas", onde a "lógica" do capital encontra um "terrivel obstáculo" (1998, p. 49-50).
} 
BRANDT, M. \& CAMPOS, N.J. Uso comum da terra e práticas ...

\section{Pós-contestado: colonização e situação das populações caboclas}

As mudanças sentidas nos anos anteriores e que se seguiram ao conflito do Contestado no alvorecer do século XX, assinalam a intensificação de um processo de transformações sócio-espaciais no planalto relacionadas principalmente à questão da terra. Da mesma forma que aponta Paulo Pinheiro Machado, em relação à subordinação de peões e agregados a fazendeiros, muitos deles "coronéis", as relações sociais praticadas, "sentidas como costumeiras e naturais pelas pessoas", eram vistas como "experiências socialmente compartilhadas" (2004, p. 95-96), expressas, por exemplo, nas formas de acesso à terra e ao uso desta e de recursos naturais em comum. Transmitidas de geração a geração, onde a oralidade exercia uma importância fundamental, se constituíam em crenças não registradas por qualquer regulamento, e que, para aquela população, de certa forma "afastada" das instâncias de poder do Estado, poderia adquirir caráter de lei, cujo emprego e suas tradições são "tão especificos e tão locais quanto as características geográficas" (THOMPSON, 2002, p. 88).

Mesmo após a Abolição da Escravatura, as relações de poder existentes entre o fazendeiro (muitos deles "coronéis") e seus peões e agregados continuavam baseando-se na propriedade da terra e, no caso do agregado, em ceder um pedaço de terra para que este possuísse sua pequena roça, além de algumas cabeças de gado, muitas delas dadas "de presente" pelo fazendeiro. Por outro lado, tanto o agregado quanto o peão possuíam um certo poder em relação ao fazendeiro, "uma vez que era cada vez mais difícil contar com um camarada leal e trabalhador", ainda mais em uma região de fronteira em expansão, como eram as matas ao oeste e norte do Planalto, que vislumbrava a estes uma oportunidade de se embrenhar na mata e construir um rancho e uma pequena roça, criando seus animais soltos no mato.

Conforme Paulo Pinheiro Machado, diferente do que ocorria na Inglaterra do século XVIII, onde E. P. Thompson observa um processo paulatino de redução da dependência da população 
BRANDT, M. \& CAMPOS, N.J. Uso comum da terra e práticas ...

plebéia em relação a gentry (burguesia fundiária), principalmente a partir de 1760, "quando se identifica uma crescente mobilidade, indisciplina e falta de controle sobre a 'vida inteira' dos trabalhadores", na região do Planalto Catarinense, observa-se a perda da autonomia desta população e sua crescente submissão ao poder dos "coronéis" e grandes fazendeiros. Embora existam grandes diferenças temporais, sociais e espaciais entre a Inglaterra do século XVIII e o Planalto da passagem do século XIX para o $\mathrm{XX}$, que vão desde uma maior hierarquização e complexidade por parte dos ingleses, se comparado à sociedade planaltina, onde existem, como aponta Paulo Pinheiro Machado, "diversos elementos históricos, políticos e culturais que devem demover-nos do intento de estabelecer comparações diretas", tal comparação é útil "para entender não apenas a natureza das relações de subordinação social, mas principalmente para qual sentido elas caminhavam" (2004, p. 99-100).

No caso da apropriação de grandes extensões de terras para o estabelecimento de grandes fazendas pastoris, segundo o mesmo autor, estas não podem ser consideradas apenas pelo fator natural, onde a baixa fertilidade do solo e a pequena reprodução bovina, somada a técnicas rudimentares de manejo do animal, implicariam em uma necessidade de grandes áreas de pastagens. Devem também ser vistas através das condições sociais, históricas e políticas, assim como em relação

ao padrão senhorial da ocupação vigente (não apenas) naquele período, no qual a grande fazenda representa a possibilidade de acúmulo de riquezas, do exercício e afirmação do poder político sobre a vizinhança e a comunidade local e, muitas vezes, sua projeção regional (MACHADO, 2004, p. 78).

Pode-se assim supor que o aumento da subordinação da população conhecida como cabocla ante o poder dos "coronéis" e grandes fazendeiros, da mesma maneira que a apropriação das terras, impedindo em alguns casos o acesso daquela população, fosse, ao longo dos anos, motivo de desestruturação de algumas 
BRANDT, M. \& CAMPOS, N.J. Uso comum da terra e práticas ...

formas consideradas tradicionais na organização e uso da terra. É claro que a desestruturação não acontece de uma só vez em todo o planalto. Em algumas regiões, é apenas a partir das décadas de 1930 e 1940 que as transformações, com diferenças espaciais, sociais e econômicas em relação ao final do século XIX, se fariam sentir, as quais, de forma semelhante à Inglaterra do século XVIII analisada por E. P. Thompson, onde a dissolução das formas tradicionais de associativismo, a apropriação da terra e o seu usufruto em comum, "ficavam a cargo da penetração das forças de mercado" (2002, p. 142).

No início, estas acompanhavam quase sempre o avanço das grandes propriedades pastoris, e mais especificamente, no Planalto Norte, a produção ervateira. É possível assinalar em tal período, que se inicia nas últimas décadas do século XIX, sobretudo a partir do período republicano, a intensificação deste processo que cada vez mais avançava em direção aos "sertões". Pode-se dizer que, em um intervalo inferior a quatro décadas, grande parte da população planaltina experimentou transformações sócio-espaciais muito mais intensas do que as que até então ocorriam no que cabe a formas de uso da terra, ao longo dos seus mais de 150 anos de ocupação, quando foram instaladas as primeiras fazendas de criação e caminhos de tropa varando o Planalto.

No caso do uso em comum de campos, matas e faxinais na criação de animais, o processo de apropriação não significa, como já alertamos anteriormente, ao menos em um primeiro momento, e em todas as áreas, o seu término. O uso comum permanecia ocorrendo tanto entre os pequenos sitiantes independentes quanto em relação aos agregados - muitos ex-posseiros - e mesmo entre grandes fazendeiros, que criavam seus animais à solta. Havia também a possibilidade de criação nas terras das grandes fazendas, que poderia, de certa forma e em alguns casos, ser vista sob o viés de mais um "favor" do "coronel". Porém, tal criação, diferente da realizada pelos sitiantes independentes, possuía certa limitação do número de animais, sempre em detrimento do agregado. 
BRANDT, M. \& CAMPOS, N.J. Uso comum da terra e práticas ...

No Planalto Norte, a situação em relação ao uso comum da terra, especificamente na extração de erva-mate, era diferente em relação a maior parte do Planalto Lageano. As apropriações, conseguidas por meio de diversos expedientes, dentre eles a grilagem e a concessão de terras por parte do governo aos "coronéis", tornavam freqüentes as expulsões de posseiros, tratados como intrusos, que acabavam partindo para novas terras ou se sujeitando a novas condições de trabalho na fazenda. Se o uso comum em relação a criação permanecia, a despeito do aumento da perda de autonomia e submissão, inseridos dentro de uma complexa relação de dominação-subordinação perante o poder dos grandes fazendeiros e "coronéis", sobretudo nas regiões onde o mate não se encontrava em número economicamente viável, reduzia-se a possibilidade da coleta em comum da erva-mate em terras devolutas nos ervais nativos. Em relação a isso comenta Maurício Vinhas de Queiroz que "a coleta do mate vinha tendendo a fazer-se cada vez mais e freqüente em terras de propriedade privada, deixaram de existir na área vastos espaços em branco à espera de ocupante" (1981, p. 64).

Os próprios proprietários de terras, se no início permitiam a coleta do mate por parte de seus peões e agregados passaram, a partir da valorização do produto, a coibi-la. Assim, à medida que a economia ervateira se desenvolvia, as terras onde se realizavam tais atividades passavam a ser alvo da apropriação privada, sendo que, segundo argumenta o autor anteriormente referido, as propriedades dos "coronéis", abrangiam "quase todos os ervais conhecidos". As terras que não eram alvo de apropriação eram arrendadas pelo Estado para sua exploração. Rosângela Cavallazzi comenta que nestes arrendamentos, com prazos de exploração variáveis, o preço do contrato se estabelecia em relação a "quantidade de erva-mate extraída, sempre com o cuidado (expresso nas cláusulas de contrato) de exigir que fosse a extração efetuada de modo a conservar os ervais e outras madeiras de qualquer espécie" (2003, p. 68). Marli Auras cita o exemplo do Decreto Lei $\mathrm{n}^{\circ} 1.273$ de 10 de janeiro de 1891, em que prevê a 
BRANDT, M. \& CAMPOS, N.J. Uso comum da terra e práticas ...

permissão para a exploração de ervais devolutos por uma empresa ervateira de Joinville pelo prazo de 20 anos em terras devolutas de diversos municípios, dentre eles Curitibanos, Campos Novos e Lages (2001, p. 30). O próprio Estado, ao adotar algumas medidas regulatórias para a extração do mate, cuja exploração se intensificava no início do século $\mathrm{XX}$, menciona o caso das concessões de ervais nativos a particulares conforme definido na Lei Estadual $\mathrm{n}^{\circ}$ 700, de 27 de outubro de 1906, que dá "providência sobre a herva matte" (SANTA CATARINA, 1906).

Cabe ressaltar, que tanto no Planalto Lageano quanto no Planalto Norte, as centenas de famílias de população cabocla, constituídas por posseiros, ex-posseiros e ex-agregados que, passado o conflito do Contestado, retornaram para as terras que originariamente ocupavam, não as encontraram mais desocupadas. A maior parte havia sido apropriada, seja por fazendeiros, por oligarquias regionais, por projetos de colonização, que passaram a ser ocupadas por imigrantes e migrantes de origem européia (alemães, italianos, eslavos) provenientes principalmente das áreas coloniais do Rio Grande do Sul, e, inclusive, por políticos e/ou elementos ligados a diferentes escalões do poder público, que, conhecendo a situação em que permaneciam as terras (em grande parte devoluta), aproveitavam para também se apoderar de áreas consideráveis.

Assim, pela dificuldade do acesso a terra, o costume de se criar animais a solta de modo comum em áreas abertas, embora ainda permanecesse em algumas áreas, situações e/ou contextos específicos, vai gradualmente desaparecendo. A colonização representou uma mudança relativamente acelerada, para a população cabocla, introduzindo valores externos àquele espaço, deixando a estes duas alternativas: adaptar-se ou ficar excluída. Como afirma Arlene Renk, a primeira seria pela desestruturação do antigo modo de vida, e a segunda pelo descompasso do habitus da população, "que não se transforma com a rapidez exigida pelas mudanças introduzidas", criando assim um descompasso com as estruturas econômicas introduzidas pelo colonizador (1997, p. 
BRANDT, M. \& CAMPOS, N.J. Uso comum da terra e práticas ...

105). A consolidação deste processo, principalmente na faixa de disputas entre o Paraná e Santa Catarina, envolvendo o Vale do Rio do Peixe e Oeste, faz com que aquele espaço fosse bastante alterado pela ação dos colonos para a produção de lavouras que, diferentemente dos antigos moradores, cuja produção era em pequena escala e destinada principalmente à subsistência, passam agora a comercialização de produtos como o trigo e o milho, cercando e reduzindo os espaços de criação dos animais. A própria vegetação nativa, com árvores como a araucária e outras árvores de grande porte existentes na região, como a imbuia e o cedro, tornam-se objeto da cobiça dos recém instalados, dando início à exploração madeireira, tanto por empresas de grande porte como a Lumber, subsidiária da Brazil Railway, quanto por pequenas serrarias, voltadas à extração e beneficiamento da madeira. Tudo isso foi marcante no processo de desagregação dos espaços onde era possível o usufruto em comum da terra para a criação, como no caso dos porcos, que passariam a ter sua circulação restrita pela formação de lavouras e florestas devastadas, passando finalmente a ser criado fechado, em encerras, ao modo praticado pelos colonos.

\section{Considerações finais}

Tinha bastante porco ali, e hoje não se vê um porco aqui na região [...]. A gente vê aí hoje, não pode ter uma galinha, não pode ter um porco, então a gente se sente um pouco desajeitado, o interesse da gente é criar.

Esta frase, proferida por Sebastião Pires (2005), antigo morador da região de Fraiburgo, expressa bem o sentimento de muitos dos antigos moradores, grande parte remanescentes do conflito do Contestado, frente ao processo de inserção de novos empreendimentos econômicos naquele espaço, resultando na redução e gradual extinção de práticas consideradas costumeiras, onde muitos, como no próprio caso de Sebastião Pires, sofreram também expropriação de suas terras. População que permanece até os dias de hoje alvo de uma invisibilização, que pode ser vista 
BRANDT, M. \& CAMPOS, N.J. Uso comum da terra e práticas ...

como uma "produção de um certo olhar que nega sua existência como forma de resolver a impossibilidade de bani-lo totalmente da sociedade" (LEITE, 1996, p. 41). São homens e mulheres cujas memórias, práticas sociais e espaciais são desqualificadas, silenciadas pelas "versões oficiais". Versões que enobrecem o empreendedor, o pioneiro, na maioria de ascendência européia, construindo uma "história dos vencedores". Estes, como enfatiza Peter Burke "podem dar-se o luxo de esquecer, enquanto os perdedores não conseguem aceitar o que aconteceu e são condenados a remoê-lo, revivê-lo, refletir como poderia ter sido diferente" (BURKE, 2000, p. 83).

É evidente que o processo de formação e dinâmica sócioespacial da região do planalto catarinense proporciona elementos que explicam a invisibilidade de sua população tradicional. No entanto, tal população, apesar de tudo, continua, em situações ou contextos específicos, a proceder atividades de cunho coletivo, como a questão do mutirão, por exemplo, e quiçá, o uso de uma ou outra área de forma comum. Ressalte-se que em muitas áreas do país, formas de uso comum da terra não só continuam a ocorrer, como inclusive a visibilidade de diversas populações tradicionais tem aumentado, haja vista a maior visibilidade jurídica, política, social e mesmo econômica a elas relacionadas, a exemplo do que é percebido em relação aos faxinais no Paraná, fundos de pastos na Bahia e formas de uso da terra por povos da floresta em diferentes espaços da Amazônia.

\section{Referências bibliográficas}

\section{Fontes orais}

CORDEIRO, Maria José. 91 anos. Depoimento, 2 de outubro de 2005, Fraiburgo. Entrevistador: Marlon Brandt.

PIRES, Sebastião. 73 anos. Depoimento, 02 de outubro de 2005, Fraiburgo. Entrevistador: Marlon Brandt. 
BRANDT, M. \& CAMPOS, N.J. Uso comum da terra e práticas ...

\section{Bibliografia}

ALMEIDA, A.W.B. Terras tradicionalmente ocupadas: processos de territorialização e movimentos sociais. In: Revista de Estudos Urbanos e Regionais. v. 6, n. 1, p. 9-32, maio 2004.

AURAS, M. Guerra do Contestado: a organização da irmandade cabocla. 4. ed. Florianópolis: Ufsc, 2001.

BURKE, P. Variedades de história cultural. Rio de Janeiro: Civilização Brasileira, 2000.

CALDEIRA, C. Mutirão: formas de ajuda mútua no meio rural. São Paulo: Companhia Editora Nacional.

CAMPOS, N.J. Terras de uso comum no Brasil: um estudo de suas diferentes formas. 2000. 258f. Tese (Doutorado em Geografia Humana) - Faculdade de Filosofia, Letras e Ciências Humanas, Universidade de São Paulo, 2000.

CÂNDIDO, A. Os parceiros do Rio Bonito: estudo sobre o caipira paulista e a transformação dos seus meios de vida. 2. ed. São Paulo: Livraria Duas Cidades, 1971.

CAVALLAZZI, R.L. Contestado: tempo do camponês, espaço da propriedade privada. Florianópolis: Fundação Boiteux, 2003.

D'ASSUMPÇÃO, H.T. A campanha do Contestado (as operações da Columna do Sul). V. 1. Belo Horizonte: Imprensa Official do Estado de Minas Geraes, 1917.

FELIPPE, E. O último jagunço: folclore na história da Guerra do Contestado. Curitibanos: Unc, 1995.

LEITE, I.B. Descendentes de africanos em Santa Catarina: invisibilidade histórica e segregação. In: LEITE, Ilka Boaventura (org.) Negros no Sul do Brasil: invisibilidade e territorialidade. Florianópolis: Letras Contemporâneas, 1996.

MELLO, J.B.F. A humanização da natureza - uma odisséia para a (re)conquista do paraíso. In: MESQUITA, Olindina Vianna; Silva, 
BRANDT, M. \& CAMPOS, N.J. Uso comum da terra e práticas ...

Solange Tietzmann (org). Geografia e questão ambiental. Rio de Janeiro: IBGE, 1993.

MICELI, S. Introdução: a força do sentido. In: BOURDIEU, Pierre. A economia das trocas simbólicas. São Paulo: Perspectiva, 2003. Coleção Estudos, n. 20

"MUTIRÃO" ou "adjunto". Boletim do Conselho Nacional de Geografia. Rio de Janeiro, ano 1, n. 2, p. 38-39, maio de 1943.

NEVES, F.C. Economia moral versus moral econômica (ou: o que é economicamente correto para os pobres?). Projeto História, São Paulo, n. 16, p. 39-57, fevereiro 1998.

QUEIROZ, M.V. Messianismo e conflito social: a guerra sertaneja do Contestado (1912-1916). 3. ed. São Paulo: Ática, 1981. Coleção Ensaios, n. 23.

RAMOS, A. O espírito associativo do negro brasileiro. Revista do Arquivo Municipal, São Paulo, n. XLVII, p. 105-126, 1938.

RENK, A.A. A luta da erva: um ofício étnico no Oeste catarinense. Chapecó: Grifos, 1997.

SANTA CATARINA (Estado). Lei $\mathrm{n}^{\circ} 700$, de 27 de outubro de 1906. Coleç̧ão de Leis do Estado de Santa Catharina. Florianópolis: Gab. Typographico d'O Dia, 1905.

SERPA, E.C. A Guerra do Contestado (1912-1916). Florianópolis: Ufsc, 1999. Coleção Rebento.

THOMPSON, E.P. A formação da classe operária inglesa: a árvore da liberdade. São Paulo: Paz e Terra, 1987.

Costumes em comum. São Paulo: Companhia das Letras, 2002.

VIEIRA DA ROSA, J. Reminiscencias da Campanha do Contestado - subsídios para a História. In: Jornal Terra Livre, Florianópolis, $\mathrm{n}^{\circ}$ 6, ano 1, 7 de agosto de 1918.

Recebido em dezembro de 2006 Aceito em julho 2007 